\title{
The relationship between individual characteristics and ideation behavior: an empirical study of storyboards
}

\author{
Pei-Shan Teng $\cdot$ Dengchuan Cai $\cdot$ Tai-Kuei Yu
}

Accepted: 20 January 2014/Published online: 12 February 2014

(C) The Author(s) 2014. This article is published with open access at Springerlink.com

\begin{abstract}
The development of digital technology tool and the progress of animation design activities have led to great progress in the animation field. The storyboard is a type of media used to present animator ideas. Therefore, it is commonly viewed as fundamental to the animation industry. This study aims to discuss cognitive style- and gender-based differences in word and image idea associations and how to create a story using word and image stimuli. Using a cognitive style index instrument, 104 university freshmen (48 males and 56 females) were classified into the four type groups of male analytic, male intuitive, female analytic, and female intuitive. Each participant was then asked to execute two design tasks: associate word and image ideas (ideational process) and develop a storyboard (ideational outcome). Four experts evaluated outcomes in terms of creativity, structure, and drawing skill. Results show that larger numbers of words and images correlate with good word and image ideas and that analytic females exhibited the greatest level of ideation and intuitive males exhibited the least.
\end{abstract}

Keywords Gender difference $\cdot$ Cognitive style $\cdot$ Ideation $\cdot$ Storyboard

\footnotetext{
P.-S. Teng

Department of Visual Communication Design, Chaoyang University of Technology, 168, Jifeng E. Rd., Wufeng District, Taichung 41349, Taiwan, ROC

e-mail: psteng09@gmail.com

D. Cai

Graduate School of Design, National Yunlin University of Science and Technology, 123 University Road, Section 3, Douliou, Yunlin 640, Taiwan, ROC

e-mail: caidc@yuntech.edu.tw

T.-K. Yu $(\bowtie)$

Department of Business Administration, National Quemoy University, 1 University Road, Jinning Township, Kinmen Hsien, Taiwan, ROC

e-mail: yutk2000@gmail.com
} 


\section{Introduction}

Digital tools are regularly employed in animation courses such as 3D max and animation software tools taught in media design, visual communication, art and other departments. Although popular with freshman undergraduates, students often lack the training and experience necessary to compose and tell a good story in animation. The difficulty these students have expressing personal ideas and creating good original narratives is also a challenge for instructors.

In the field of animation, "storyboards" provide continuity of action using a series of illustrations or images displayed in sequence. Canemaker (1999) noted that storyboards were first developed at Disney in the 1920s and use "story sketches" to create a comic book flow to illustrate an animated cartoon storyline. Finch (1973) indicated storyboards are an important communication tool for film directors, storyboard artist, cinematographers, and television commercial advertising clients. Storyboarding provides a standard method of pre-visualization that is widely used in films, animations, and advertisements and in the interactive media field with games and websites. In design education, sketching is the most typical method used to present ideas during the design thinking/ideation process.

Some researchers have indicated that the sketch method can help designers refine their concepts across different but related ideas. Relational studies of sketching have included comparisons of traditional sketches and computer sketches (Stones and Cassidy 2007; Chen and You 2006) and differences between novices and professionals in handling the same architectural tasks (Lawson and Menezes 2006). Concept sketch is a core course taught in the architecture, industrial design, and graphic design fields. Sketch methods can thus help novice learner generate key ideas and dynamic-images and arrange them in sequence on storyboards.

Content developed in the storyboard process primarily involves role action, different shots, and description or postscript text. Although Segers et al. (2005) indicated that word stimulus is more easily ignored than image stimulus in the design ideation process, his study showed the former as more effective in developing ideas. Both words and images are thus important in describing ideation elements in the storyboard format. However, there is a lack of discussion in the literature regarding the process of creating stories in the animation field. Few studies have investigated the impact of basic elements such as words and images across the entire process, from concept ideation to the completed storyboard.

In addition, individual cognitive styles and gender differences have both been identified as factors of influence in learning performance (Demirbas and Demirkan 2007; Okudan and Mohammed 2006; Roberts 2006). Okudan and Mohammed (2006) indicate that gender is associated with differences in learning methods, performance, specialties, and attitudes. From an educational viewpoint, the development of personal abilities can enhance learning interest and lead to greater achievement through the use of appropriate learning methods. Based on the above discussion, this study aimed to answer the following questions:

1. Can more ideation elements within words and images help stimulate novice learners generate more good ideas?

2. How does gender and cognitive style affect an individual's ideation performance?

The remainder of this paper is organized as follows. "Ideation study" section provides a review of the literature based on theoretical and empirical rationales. The research methodology and experimental program are provided in "Research method" section. "Results and discussion" section outlines the data analysis techniques and presents the 
results. Finally, "Conclusions" section discusses implications of the findings, as well as ideas for future research.

\section{Ideation study}

Sternberg and Grigorenko (1997) proposed a theory of two thought-related categories: conceptual thinking and image thinking. The former is strongly associated with abstraction, verbalization, and words. The latter is strongly associated with sketches, pictures, and figures. However, words seem to receive less attention than images in a majority of design education processes and practices (Segers et al. 2005). Segers et al. (2005) thinks that designs are developed through a series of sketches, images, annotations, and marks. Sketch annotations include comments, questions, descriptions, explanations, expressions, and diagrams. Words are constantly instilled with subtly different meanings and interpretations in the early phase of the ideational process. Words and sketches share a similar purposeto provide the designer with additional visual cues useful in building the narrative structure. In this study, we define ideation elements in terms of semantic associations (words) found in annotations and pictorial associations (images) pertaining to the sketching process.

Some scholars offer different viewpoints on how to evaluate creative performance (Christiaans 1992; Van der Lugt 2001; Liu and Bligh 2003). Liu and Bligh (2003) stated that a good designer should have three feature-based abilities: integration, judgment, and practice. Guilford (1968) stated that creativity includes divergent thinking and convergent thinking. Guilford's results influenced the Torrance Test of Creative Thinking (TTCT) method in terms of its use of four major features (fluency, flexibility, originality, and elaboration) to evaluate creative ideas (Torrance 1974; Purcell and Gero 1996; Segers et al. 2005). Referencing the above studies, the present study used number of ideation elements, creativity, structure, and skill ability as evaluative standards.

\section{Individual differences: cognitive style and gender}

Differences in personal characteristics affect cognitive ability. Some researchers have focused on cognitive style models to find out more about individual characteristics. Schmeck (1988) suggested that some researchers focus on global thinking while others prefer more analytic thinking. Riding and Cheema (1991) pointed out differences between those who organize information as wholes (labeled 'wholists') and those who break down information into smaller parts (labeled 'analytics'). Further, Allinson and Hayes (1996) argued that cognitive style forms a bipolar dimension between a tendency for an individual to think analytically (labeled 'analytic') and a tendency for an individual to think intuitively (labeled 'intuitive').

Many researchers have suggested that an individual's cognitive style may be relevant to their academic performance in the field of design (Roberts 2006; Yukhina 2007). Roberts (2006) indicated that architecture students associated with different cognitive styles performed differently in terms of overall academic performance. Although first-year analytics scored higher than both first-year wholists and intermediates, the three groups scored similarly in their final year. These results echo those of Yukhina (2007), who compared the cognitive styles and academic performances of architecture students in Sydney. Both sets of results suggest that analytics perform better, but only during the early stages of learning. 
There have been a few studies on gender differences in design education. Demirbas and Demirkan (2007) performed a gender comparison of design students in terms of academic performance scores (grade point average [GPA]). Their results show that males performed better in technology-based courses and females scored higher in artistic and fundamental courses as well as in overall academic performance scores. Okudan and Mohammed (2006) investigated the impact of gender orientation on design tasks and teaching methods. Their results suggest that gender orientation exists in terms of various work attributes. They found that males outperformed females on an engineering task (designing an air velocity controller). They also found, however, that males and females had similar levels of technical knowledge.

\section{Research method}

In order to investigate the relationship between each ideation element (words and images) and a complete storyboard, a one-way of variance analysis (ANOVA) and Chi square were employed to analyze how the dependent variables (creativity, structure, and drawing skill) influence ideation behavior and performance in terms of producing a storyboard. Student's cognitive style and gender were employed as independent variables. Participants' cognitive style data was grouped using clustering analysis to be more understandable and to normalize the information more efficiently. In total, 104 students from the department of Digital Media Design at Asia University in Taiwan participated in this study. All of them were freshmen with little sketch drawing experience. Participant genders were approximately equal: $48(46.2 \%)$ males and $56(53.8 \%)$ females. The average age was 21.6 years old $(\mathrm{SD}=1.9)$.

\section{Cognitive style instrument}

Based on the Cognitive Style Index (CSI) developed by Allinson and Hayes (1996), the modified measurement instrument used in this study by simplifying the test questions ( $\mathrm{Yu}$ 2006). $\mathrm{Yu}$ indicated the 10 attribute items measured questions were more appropriate for the cognitive level of college students in Taiwan. Students responded on a 7-point Likert scale anchored by 7 (high) and 1 (low), where the higher the predominating score mean, the stronger the preference. The descriptive scale and instrument statistics are shown in Table 1. A reliability analysis (Cronbach's alpha) was performed to test the reliability and internal consistency of each of the 10 attribute items measured. The results show that the alpha coefficients for all 10 attribute items were high, ranging from 0.811 to 0.835 . The results presented in Table 1 attest to the high internal consistency of the instrument, in that all values are above the suggested 0.70 level for scale robustness (Nunnally and Berstein 1994). We used cluster analysis techniques to examine the participants' cognitive style across the survey data; in total, $48(46.2 \%)$ students were determined to be analytic while $56(53.8 \%)$ were rated as intuitive. Cognitive style measurement variables for the intuitive and analytic types were classified using K-means (see Table 1). Moreover, exploratory factor analysis established validity for both analytic and intuitive groups, as shown in Table 1. Cronbach's alphas were all high and within acceptable ranges. We performed exploratory factor analysis (EFA) to conduct all data analysis. We first conducted the Kaiser-Meyer-Olkin (KMO) and Bartlett's test because these methods have been widely used in previous studies to test the strength of correlations among variables prior to conducting EFA. Obtained results, a KMO index of 0.802 and Bartlett's test of sphericity 
Table 1 The items of cognitive style and the results of cluster analysis and cronbach's $\alpha$

\begin{tabular}{lllllll}
\hline No & Items & Analytics-mean & Intuitives-mean & $t$ test & \multicolumn{2}{c}{ Cronbach's $\alpha$} \\
\hline 1 & I enjoy thinking deeply & 4.38 & 3.13 & $7.52^{*}$ & 0.835 & 0.811 \\
2 & I enjoy handling complicated problems & 3.96 & 3.27 & $4.38^{*}$ & & \\
3 & I enjoy new challenges & 3.52 & 2.25 & $7.52^{*}$ & & \\
4 & I enjoy focusing on one thing & 4.04 & 2.88 & $6.53^{*}$ & & \\
5 & I trust my first impression & 3.98 & 2.67 & $7.35^{*}$ & \\
6 & I prefer to depend on foresight & 4.09 & 3.17 & $4.96^{*}$ & 0.820 & \\
7 & I prefer to depend on feelings & 3.57 & 2.85 & $3.84^{*}$ & & \\
8 & I prefer to depend on intuition & 3.52 & 2.81 & $4.17^{*}$ & & \\
9 & I depend on intuition to act & 3.68 & 3.29 & $2.03^{*}$ & & \\
10 & I enjoy thinking deeply & 3.88 & 3.10 & $4.58^{*}$ & & \\
\hline
\end{tabular}

$* p<0.05$

score of 411.832, were significant $(p \leq 0.001)$ and justified using EFA. We next conducted a principal axis analysis with orthogonal rotation to elicit the factor structure. A two-factor with separate solutions was loaded throughout this process. Analysis results showed two main factors with eigenvalues larger than 1.0 and variances of $31.101 \%$ and $29.873 \%$, respectively (cumulative percentage: $60.975 \%$ ).

Further, we included gender differences in our comparisons in order to obtain four groups: 29 students were male analytics (MA), 19 were male intuitives (MI), 27 were female analytics (FA), and 29 were female intuitives (FI).

\section{Quasi-experimental design}

The aim of this study was to better understand the difference and relationships between the ideation elements (words and images) and the storyboard comparison across the four groups: female intuitives (FI), female analytics (FA), male intuitives (MI), and male analytics (MA). The subject of the design task was "Hand". All participants had to complete the cognitive style assessment scale before beginning on the design task. Also, participants were informed of all rules that applied to the experimental process, including the time constraints associated with each part and that they had to depict their creative ideas on the prepared sheet of A4 paper. Every participant was given 90 min to complete the entire process: 20 min for each word and image elements creation, and $50 \mathrm{~min}$ to produce a completed storyboard. The experiment process consisted of two parts: (1) ideation elements associated with words and images, and (2) a complete short story consisting of ten scenes on a storyboard.

In addition, we wanted to let participants maximize the natural presentation of their ideation within the lab-based experimental setting. For the first task associated with words, participants were asked to freely associate any words with the subject (hands), including descriptive objects (nouns), feelings (adjectives) or concepts (sentences). As for the ideations of images, participants were permitted to sketches anything that they felt was related to the subject, including shapes (e.g. geometrical or realistic images), imaginative images (combinations of different objects, e.g. using hand shadows to create a bird shape) and symbols (e.g. holding hand to symbolize a warm heart).

For the storyboard task, each participant was asked to create a complete story in their storyboard. Moreover, each participant was asked to refer to their associative word and image elements from the first task to assist them in producing their new story. The scene 
process had to be presented within the storyboard template. Ten major visual scenes were to be showed on the left side of the storyboard template, and voiceovers (OS, voice annotations) or notes were permitted on the right side.

Evaluative work

Many scholars have proposed similar ways of evaluating the amount of good ideation in student's work; Guilford's (1968) thinking model theory pertains to both divergent thinking in terms of the variety of dimensions in the early phase of ideation, and convergent thinking in terms of the later stages of strategic decision. These two different types of thinking are alternately applied during the thinking process until an optimal solution is reached (Cross 1994; Van der Lugt 2001). Accordingly, we identified all ideation elements and complete solutions, and then calculated the number of primary words ideas primary words ideas (PWs) and primary images ideas primary images ideas (PIs). Next, four experts evaluated the primary words ideas (PWs) and primary images ideas (PIs), and computed the amount of good word ideas good word ideas (GWs) and good image ideas good image ideas (GIs) based on Guilford's (1968) aforementioned divergent and convergent thinking categories; the divergent thinking category contained a greater variety of good ideas. Table 2 includes examples of divergent and convergent thinking ideas.

There are three valuation variables for storyboards: creativity, structure and drawing skill. Operational definitions of these evaluation criteria are as follows:

(1) creativity The story's theme, view, or content is creative or special ideas. (2) structure refers to a complete story based on Clearly context structure in the storyboard.; and (3) drawing skill Skill Ability is defined drawing or expression technique for story's role and background need etc. Refer to focus group define four level evaluation scores: 1-2, 3-5, 6-8, and 9-10, each expert evaluation ranged from one (lowest) to ten (highest). Expert evaluations are commonly used when evaluating student performance. In addition, the experts used in our study were as follows, one was an animator with 14 years of work experience; another was a role designer with 10 years of work experience; and the other two were teachers from the Media Design Department with over seven years of teaching experience.

\section{Results and discussion}

The relationship among the variables in this study was tested using SPSS 10.0. The mean percentile-ranks for each group were calculated and ANOVA was used to test for significant differences between the ranks in each group. In addition, the date analysis was divided into two sections: ideation elements and storyboard performance.

Evaluation results for ideation elements

The measurement model of ideation elements was validated from four items: primary words ideas (PWs), primary images ideas (PIs), good word ideas (GWs), and good image ideas (GIs). As depicted in Table 3, it shows the mean for each group in words and images, making it easier to compare results. Female analytics (FA) earned the highest score in premier words (8.44), good idea words (3.69), premier images (5.25), and good idea images (2.60). Female intuitives (FI) ranked second in premier words (8.23), good idea words (3.41), premier images 
Table 2 Examples of divergent thinking and convergent thinking in this experiment

Divergent thinking Convergent thinking

Words Hands shadows create Fist be presented right Warm Happiness

bird shape
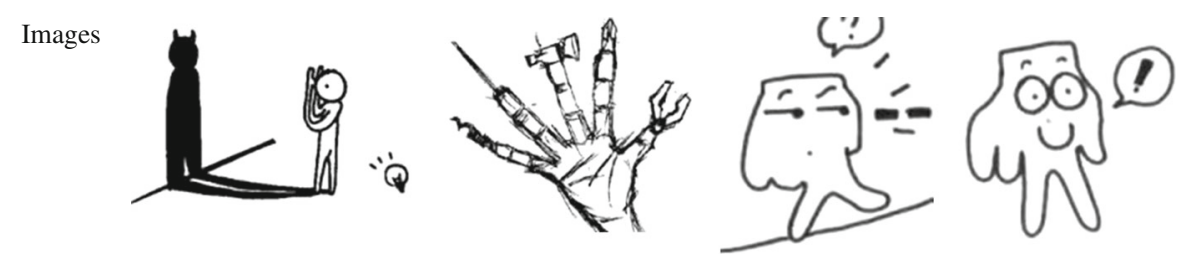

(5.15), and good idea images (2.20). Male analytics (MA) ranked third in premier words (8.04), good idea words (2.91), premier images (4.54), and good idea images (2.07). Male intuitives (MI) ranked fourth rank in premier words (7.26), good idea words (2.91), premier images (4.07), and good idea images (1.57). Moreover, analytics scored higher than intuitives in both gender categories. In sum, female analytics (FA) and female intuitives (FI) both scored significantly higher than their male counterparts in word and image parts.

In terms of image ideation elements, female intuitives (FI) (149.25) exhibited the greatest amount of primary images ideas (PIs), followed by female analytics (FA) (141.75), male analytics (MA) (131.75) and male intuitives (MI) (77.25), as shown in Table 3. The experts evaluated female analytics (FA) (70.25) as having the greatest amount of good image ideas (GIs), while male intuitives (MI) (29.92) had the least. In addition, female analytics (FA) $(49.56 \%$ ) had the highest average scores, followed by male analytics (MA) $(45.67 \%)$, female intuitives (FI) $(42.71 \%)$ and male intuitives (MI) $(38.73 \%)$. According to the word association-based results, females had greater ideation ability than males. For the image association-based results, female analytics (FA) and male analytics (MA) received slightly higher ranking than female intuitives (FI) and male intuitives (MI), which suggests that analytics outperformed intuitives in terms of good image ideas (GIs).

Further, comparisons across the four groups show that female analytics (FA) did not have the greatest amount of primary words ideas (PWs) in the early stages; however, this group did have the highest final average scores for both good word ideas (GWs) and good image ideas (GIs). Female intuitives (FI) had the greatest amount of primary words ideas (PWs), followed by male analytics (MA). Male intuitives (MI) had the lowest scores for both primary words ideas (PWs) and primary images ideas (PIs), with means similar to those of male analytics (MA). The results of participant outcomes across genders and cognitive styles are shown in Table 4. Moreover, the ANOVA results indicate that differences in the good word ideas (GWs) and good image ideas (GIs) between the groups were significant, as shown in Table 5. Female analytics (FA) outperformed male analytics (MA) in good word ideas $(\mathrm{GWs})\left(\mathrm{F}_{(3,100)}=1.8042, p<0.05\right)$ male intuitives $(\mathrm{MI})$ in good image ideas $(\mathrm{GIs})\left(\mathrm{F}_{(3,100)}=2.457, p<0.05\right)$. 
Table 3 Each group person means in words and images

\begin{tabular}{lllll}
\hline & Male analytics (MA) & Male intuitive (MI) & Female analytics (FA) & Female intuitive (FI) \\
\hline PW/ave & 8.04 & 7.26 & 8.44 & 8.23 \\
GW/ave & 2.91 & 2.91 & 3.69 & 3.41 \\
PI/ave & 4.54 & 4.07 & 5.25 & 5.15 \\
GI/ave & 2.07 & 1.57 & 2.60 & 2.20 \\
\hline
\end{tabular}

PW/ave = each group person means(ave) in premier words; GW/ave $=$ each group person means(ave) in good idea words; PI/ave = each group person means(ave) in premier images; GI/ave = each group person means(ave) in good idea images

Table 4 Relationship between ideational elements with a complete storyboard across the four groups (participants outcomes)

Male

Results for evaluation storyboards

The Levene test of variances across the four groups failed to reach significance. A post hoc comparison of the LSD test (Fisher's Least Significant Difference) shows that the means for creativity and drawing skill between the groups were significant, as depicted in Table 5. The female analytics (FA) and female intuitives (FI) creativity scores exceeded that of male analytics $(\mathrm{MA})\left(\mathrm{F}_{(3,100)}=2.852, p<0.05\right)$. Moreover, female analytics $(\mathrm{FA})$ had higher scores in drawing skill $\left(\mathrm{F}_{(3,100)}=2.868, p<0.05\right)$ than both male analytics (MA) and male intuitives (MI). However, no significant differences were noted between the groups in terms of structure.

A comparison of the evaluation variable means of the four groups is depicted in Figure 1. These results show that females outperformed males in terms of both ideation 
Table 5 Summary of ANOVA results for all variables

\begin{tabular}{lllllll}
\hline Part & Variable & SS & df & MS & F & In groups \\
\hline Ideation elements & Good word ideas (GWs) & 11.313 & 3 & 3.771 & $1.804^{*}$ & FA $>$ MA \\
& Good image ideas (GIs) & 12.029 & 3 & 4.01 & $2.457^{*}$ & FA $>$ MI \\
Storyboard & Creativity & 18.132 & 3 & 6.044 & $2.852^{*}$ & FA $=$ FI $>$ MA \\
& Structure & 2.254 & 3 & 0.751 & 0.15 & \\
& Skill ability & 8.340 & 3 & 2.78 & $2.868^{*}$ & FA $>$ MA $=$ MI \\
\hline
\end{tabular}

$* p<0.05$

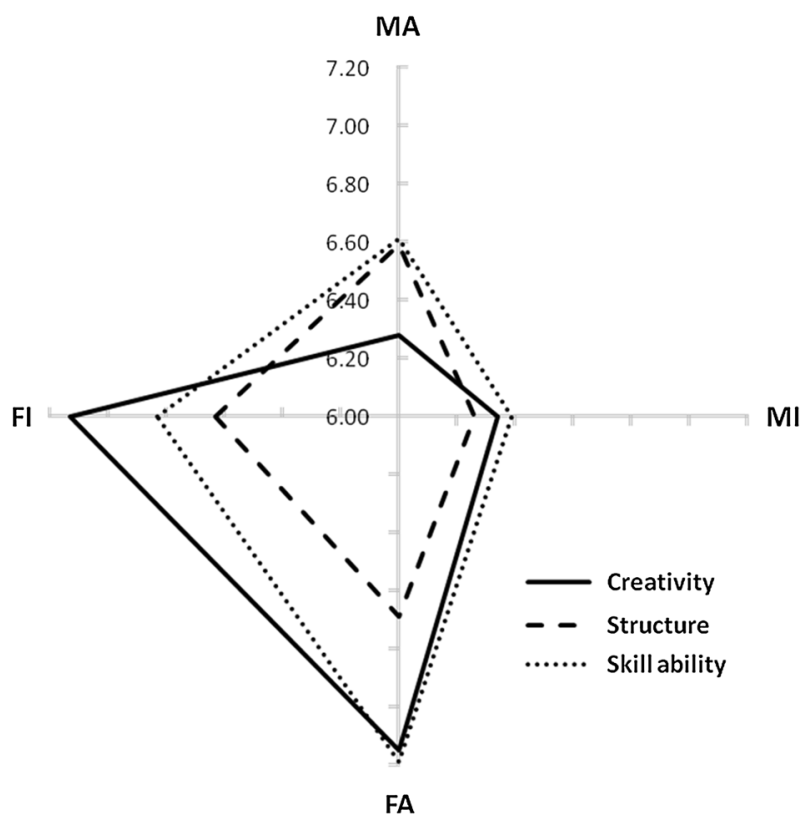

Fig. 1 Comparison score results for creativity, structure and drawing skill variables across four groups

elements and evaluated variables in storyboards: for almost all of the evaluated variables, female analytics (FA) received the best score, followed by female intuitives (FI), male analytics (MA) and male intuitives (MI). However, structure scores across the four groups were quite similar: females average scores (6.66) slightly exceeded those of males (6.46) as shown in Table 6. Male analytics (MA) received a wide variety of scores, coming second to female intuitives (FI) in structure and drawing skill, and receiving the lowest score in creativity. Male intuitives (MI) had the lowest scores for most evaluation variables, as well as the least amount of word and image ideations. While male intuitives (MI) had a slightly higher creativity score than male analytics (MA) and an equivalent GW score, male intuitives (MI) seems to have improved their thinking methods during the ideation stage.

In sum, the results indicate that females are associated with more stable performances and higher scores than males during both development processes. Moreover, analytics received higher scores intuitives. These results indicate that both gender and cognitive styles affect the amount of ideation elements and storyboard performance for novice 
Table 6 Comparison means of ideation elements and performance evaluation across gender and cognitive style

\begin{tabular}{|c|c|c|c|c|c|c|c|}
\hline \multirow{2}{*}{$\begin{array}{l}\text { Part } \\
\text { Gender }\end{array}$} & \multirow[t]{2}{*}{ CSI } & \multirow{2}{*}{$\begin{array}{l}\text { Sample } \\
\text { size }\end{array}$} & \multicolumn{2}{|c|}{ Ideation elements } & \multicolumn{3}{|l|}{ Storyboard } \\
\hline & & & $\begin{array}{l}\text { Good word } \\
\text { ideas (GWs) }\end{array}$ & $\begin{array}{l}\text { Good image } \\
\text { ideas (GIs) }\end{array}$ & Creativity & Structure & $\begin{array}{l}\text { Skill } \\
\text { ability }\end{array}$ \\
\hline \multirow[t]{3}{*}{ Male } & MA & 29 & 2.91 & 2.07 & 6.28 & 6.59 & 6.61 \\
\hline & MI & 19 & 2.91 & 1.57 & 6.34 & 6.26 & 6.39 \\
\hline & Total & 48 & 2.91 & 1.88 & 6.30 & 6.46 & 6.53 \\
\hline \multirow[t]{3}{*}{ Female } & FA & 27 & 3.69 & 2.60 & 7.15 & 6.69 & 7.19 \\
\hline & FI & 29 & 3.41 & 2.20 & 7.13 & 6.63 & 6.83 \\
\hline & Total & 56 & 3.54 & 2.39 & 7.14 & 6.66 & 7.00 \\
\hline
\end{tabular}

Bold values denote highest mean/score among four groups

designers. The amount of primary words ideas (PWs) and primary images ideas (PIs) is directly proportional to the outcomes of good word ideas (GWs) and good image ideas (GIs), which implies that word- and image elements may influence the thinking process associated with storyboard performance.

\section{Discussion}

Most researchers (Goldschmidt 1992, 1994; McGown et al. 1998; Suwa et al. 2000; Dorst and Cross 2001; Cross 2004; Lawson and Menezes 2006) have suggested that the process of sketching allows designers to "see" more visual clues and derive more idea associations. Lawson \& Menezes (2006) used an empirical approach in the design conceptual sketches. Their study results found the creative outcomes correlated with good ideation process. In addition, they found those good ideas could help designer deal with difficult design problems. These results point to the ideation process as an important step in all design activities, including that in the arenas of animation and advertisement. Conceptual sketches can help novice learners and designers identify key ideas and trigger mental images during the process of creating a complete storyboard.

Stones (2007) suggests that expressing primary words or images on paper during the ideation step, can help designers find additional solutions to mark made. In comparison, creating a new story without referring to an existing script and producing an advertisement are very difficult tasks for novices. The results of this study thus provide empirical evidence that the outlined approach may help novices develop new ideas that can then be applied to creating an advertisement or short animation piece. Web technology tools provide students with a variety of web platforms and choices for sharing their creative output.

Other studies discussed the cognitive style and learning characteristics of design collage students. Peterson and Sweitzer (1973) and Durling et al. (1996) categorized design students as "field dependent" (intuitives). Bergum (1977) identified architecture students as more likely to be "field independent" (analytics) than business students. Roberts (2006) found first-year (freshman) analytic design students performed better than their intermediate and wholist peers during the early learning stage. Demirbas and Demirkan (2007) stated a similar opinion regarding gender differences in terms of semester academic 
performance scores, with male students performing better in engineering and technology courses and female students performing better in art and design courses.

The studies of Roberts (2006) and Demirbas and Demirkan (2007) thus support the findings of the present study, which indicate statistically significant differences in good word, image, and storyboard ideas among the four groups. Female analytics (FA) and female intuitives (FI) earned higher word and image idea scores than their male counterparts. Both male (MA \& MI) and female analytics (FA) generated significantly more good word and image ideas than their intuitive peers. Overall score ranking in this category from highest to lowest was: female analytics (FA), female intuitives (FA), male analytics (MA), and male intuitives (MI). Rankings were similar for creativity and drawing skill variables as well. Scores for the structure variable were similar for all four groups. One possible reason for this latter finding is that all freshman students lacked logical training in story structure. Second-year courses such as article writing should improve training and skills.

\section{Conclusions}

Findings clearly demonstrate that cognitive style and gender can impact ideation content and outcomes. In addition to gender, cognitive type is also a factor that influences learning differences, especially in the realm of design education, where students must learn to handle complex information and images in order to generate new ideas and design outcomes.

The impact of external tool use on creative cognitive processes is an important topic of study in design research and design education. The linguistic deterministic stance in design research, implying that the graphic language used affects the designer's response to a design task, still persists. Together these aspects of sketching help move the designer from one preliminary idea to another as the designer 'sees' new ideas in existing sketches. Goldschmidt (1992) described this process as reinterpretation and saw the sketch as playing an important role in the design process. Not only does the sketch reduce memory loading, it also stimulates design thinking through various stimuli such as words and images. Specifically, this paper contributes empirical results that suggest a possible approach to help novice learners develop new ideas helpful to creating advertisement ideas and short animation pieces.

A limitation of this study is the artificial nature of the experiment. The short duration of the experiment denied novice designers adequate time to prepare-usually a vital element in the design process. Also, cognitive-style researchers typically either use long-term observational methods or compare their performance with that of novices and experts. However, the wide range of different ideational behaviors present within the study group received limited treatment in the study, which focused only on differences among the four groups in terms of ideational content. We further used a small sample size of 104 because of the timeintensive nature of both experiment and evaluation phases. Participants required approximately 90 min each to complete the three experiment tasks and experts used significantly more time to evaluate each participant's results. It is recommended that future studies include students from multiple institutions and various disciplines such as graphic design, illustration, and art to offer more detailed teaching and assessment methods.

Acknowledgments The author thank the National Science Council of Taiwan for financially supporting this research under contract NSC 99 -2511-S-507 -001 -MY2. 
Open Access This article is distributed under the terms of the Creative Commons Attribution License which permits any use, distribution, and reproduction in any medium, provided the original author(s) and the source are credited.

\section{References}

Allinson, C. W., \& Hayes, J. (1996). The cognitive style index: A measure of intuition- analysis for organizational research. Journal of Management Studies, 33, 119-135.

Bergum, B. O. (1977). Undergraduate self perceptions of creativity and independence. Perceptual and Motor Skills, 44, 187-190.

Canemaker, J. (1999). Paper dreams: The art and artists of Disney storyboards. New York: Hyperion.

Chen, H. H., \& You, M. (2006). Comparison of sketching activities with traditional and digital tools in graphic design. Journal of Design, 11(4), 113-135.

Christiaans, H. H. C. M. (1992). Creativity in design: the role of domain knowledge in designing, $\mathrm{PhD}$ Thesis. Delft University of Technology, Delft, The Netherlands: Lemma BV.

Cross, N. (1994). Engineering design methods, strategy or product design. UK: Wiley.

Cross, N. (2004). Expertise in design: An overview. Design Studies, 25(5), 427-441.

Demirbas, O., \& Demirkan, H. (2007). Learning styles of design students and the relationship of academic performance and gender in design education. Learning \& Instruction, 17, 345-359.

Demirkan, H., \& Osmandemirbas, O. (2008). Focus on the learning styles of freshman design students. Design Studies, 29(3), 254-266. doi:10.1016/j.destud.2008.01.002.

Dorst, K., \& Cross, N. (2001). Creativity in the design process: Co-evolution of problem solution. Design Studies, 22(5), 425-437.

Durling, D., Cross, N., \& Johnson, J. (1996). Personality and learning preferences of students in design and design-related disciplines. IDATER 96. Loughborough University.

Finch, C. (1973). The art of Walt Disney: From Mickey mouse to the magic kingdoms. New York: Abrams.

Goldschmidt, G. (1992). Serial sketching: visual problem solving in designing. Cybernetics \& System: An International Journal, 23, 191-219.

Goldschmidt, G. (1994). On visual design thinking: the visual kids of architecture. Design Studies, 15(2), $158-174$.

Guilford, J. P. (1968). Intelligence, creativity, and their educational implications. San Diego: Knapi.

Lawson, B., \& Menezes, A. (2006). How designers perceive sketches. Design Studies, 27(5), 571-585.

Liu, Y. C., \& Bligh, T. (2003). Towards an "ideal" approach for concept generation. Design Studies, 24(4), $341-355$.

McGown, A., Green, G., \& Rodgers, P. (1998). Visible ideas: information pat- terns of conceptual sketch activity. Design Studies, 19(4), 431-453.

Nunnally, J. C., \& Berstein, I. H. (1994). Psychometric theory (3rd ed.). New York: McGraw-Hill Publishing Company.

Okudan, G., \& Mohammed, S. (2006). Task gender orientation perceptions by novice designers: implications for engineering design research, teaching and practice. Design Studies, 27(6), 723-740.

Peterson, J. M., \& Sweitzer, G. (1973). Field independent architecture students. Perceptual and Motor Skills, 36, 195-198.

Purcell, T. A., \& Gero, J. S. (1996). Design and other types of fixation. Design Studies, 7(4), 363-383.

Riding, R. J., \& Cheema, I. (1991). Cognitive styles-An overview and integration. Educational Psychology, 11(3-4), 193-215. doi:10.1080/0144341910110301.

Roberts, A. (2006). Cognitive styles and student progression in architectural design education. Design Studies, 27(2), 167-181.

Schmeck, R. R. (Ed.). (1988). Learning strategies and learning styles. Perspectives on individual differences. New York, NY: Plenum Press.

Segers, N, de Vries, B., \& Achten, H. (2005). Do word graphs stimulate design? Design Studies, 26(6), $625-647$.

Sternberg, R. J., \& Grigorenko, E. L. (1997). Are cognitive styles still in style? American Psychologist, 52(7), 700-712.

Stones, C., \& Cassidy, T. (2007). Comparing synthesis strategies of novice graphic designers using digital and traditional design tools Purchase. Design Studies, 28(1), 59-72.

Suwa, M., Gero, J., \& Purcell, T. (2000). Unexpected discoveries and S-invention of design requirements: Important vehicles for a design process. Design Studies, 21(6), 539-567. 
Torrance, E. P. (1974). The torrance tests of creative thinking: Technical-norms manual: Bensenville. IL: Scholastic Testing Services.

Van der Lugt, R. (2001). Sketching in design idea generation meetings, Ph.D. thesis, Technische Universiteit Delft, the Netherlands.

Yu, T. K. (2006). An empirical study of web-based learning adoption in the behavioral and cognitive style. Journal of Education \& Psychology, 29(4), 687-717.

Yukhina, E. (2007). Cognitive abilities and learning styles in design processes and judgements of architecture students. Ph.D thesis, The University of Sydney, Australia. 